\title{
Dense and Low Oxygen Permeability Bilayer Ceramic Interconnect for Tubular Anode-support Solid Oxide Cells
}

Xin Yang", a, b, Peng Qiü, a, Nansheng Xu ${ }^{\text {a }}$, Lichao Jia ${ }^{\mathrm{c}}$, Lei Alexander Zhang ${ }^{\mathrm{d}}$ *, Kevin Huang $\mathrm{a}, *$

a Department of Mechanical Engineering, University of South Carolina, Columbia, SC 29208, USA

${ }^{\mathrm{b}}$ Pacific Northwest National Laboratory, 902 Battelle Blvd, Richland, WA99352, USA

${ }^{\mathrm{c}}$ Center for Fuel Cell Innovation, School of Material Science and Engineering, State Key Lab of Material Processing and Die \& Mold Technology, Huazhong University of Science and Technology, Wuhan, 430074, China

${ }^{\mathrm{d}}$ Department of Mechanical Engineering, Carnegie Mellon University, Pittsburgh, PA, 15213

*Corresponding author: sjtuzhanglei@gmail.com, huang46@cec.sc.edu

\# These authors contributed equally. 

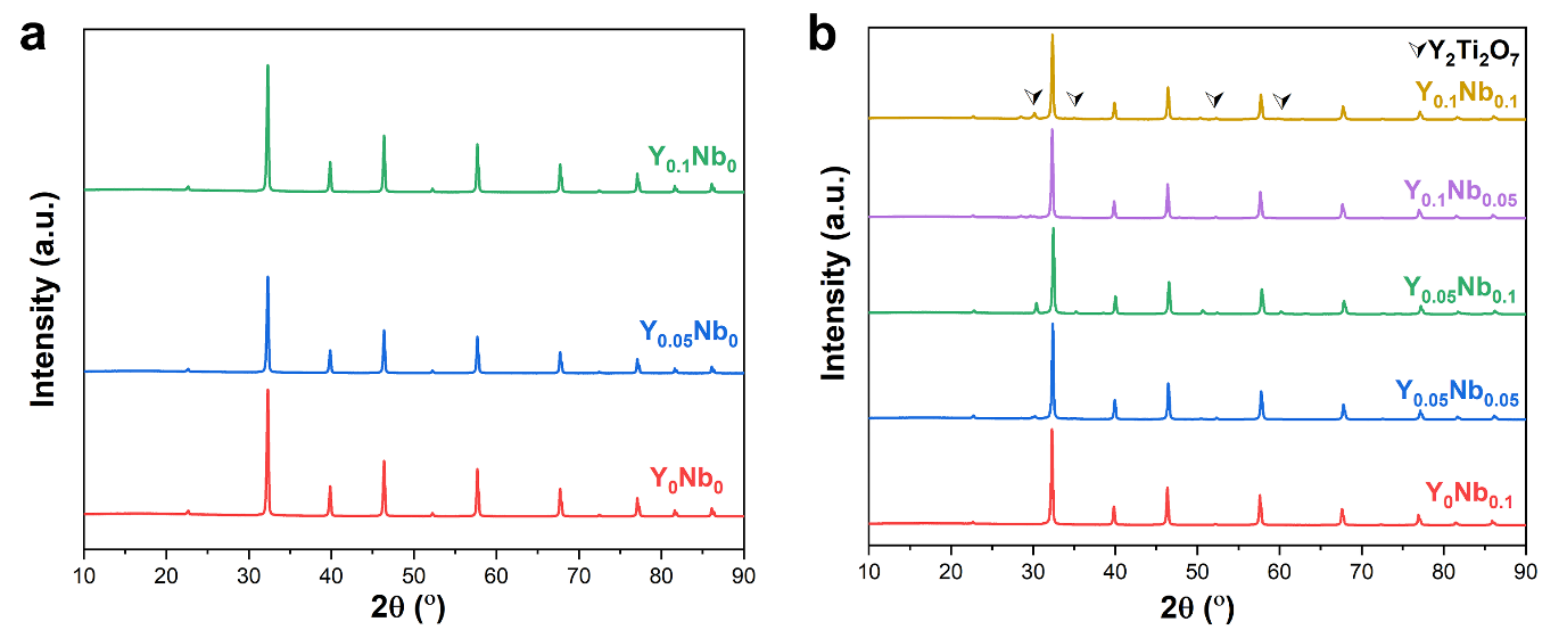

Figure S1 XRD patterns of SYTN series with different contents of $\mathrm{Y}$ and $\mathrm{Nb}$ calcined at $1300{ }^{\circ} \mathrm{C}$ for $10 \mathrm{~h}$ in air. (a) Single $\mathrm{Y}$ doping; (b) $\mathrm{Y}$ and $\mathrm{Nb}$ co-doping.

In the undoped $\mathrm{SrTiO}_{3}$, the oxidation state of $\mathrm{Sr}$ and $\mathrm{Ti}$ are bivalent and tetravalent, respectively.

Donor doping on both Sr- and Ti-sites is available to enhance electron conductivity. To ensure single-phase composition, the doping content of both $\mathrm{Y}(\mathrm{x})$ and $\mathrm{Nb}(\mathrm{y})$ are chosen to be $\leq 0.1$. A series of SYTN compositions were first calcined at $1300{ }^{\circ} \mathrm{C}$ for $10 \mathrm{~h}$ in air. Figure S1a shows that single Y-doped $\mathrm{SrTiO}_{3}$ with $x=0.05$ and 0.1 remains single phase and no impurity phases were observed. However, the doping of $\mathrm{Nb}$ on the Ti- site seems to be more difficult than Y-doping on the Sr- site. Various amount of $\mathrm{Y}_{2} \mathrm{Ti}_{2} \mathrm{O}_{7}$ impurity was observed in all samples with $\mathrm{Nb}$ doping (Figure S1b). Moreover, the impurity content increases with $\mathrm{Y} / \mathrm{Nb}$ doping content. 

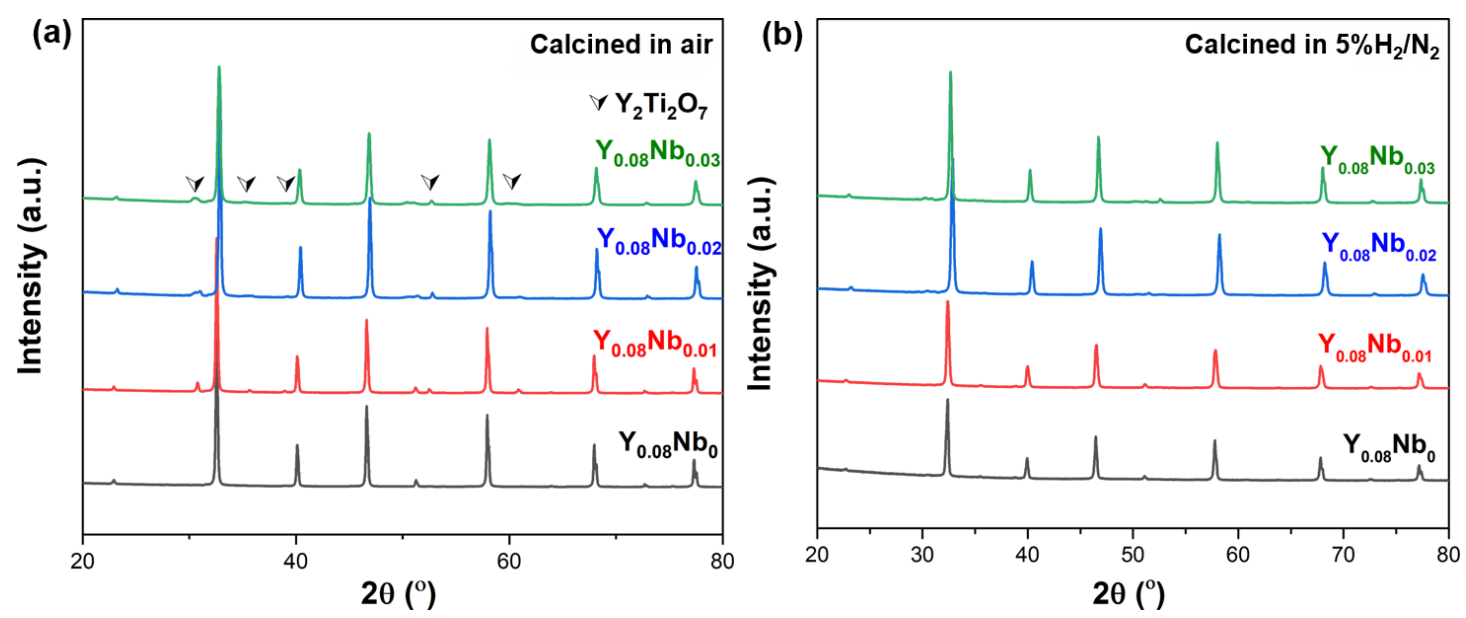

Figure S2 XRD patterns of SYTN series $(x=0.08,0 \leq y \leq 0.03)$ prepared in air (a) and in $5 \% \mathrm{H}_{2} / \mathrm{N}_{2}(\mathrm{~b})$.

Partial substitution of $\mathrm{Sr}^{2+}$ with $\mathrm{Y}^{3+}$ in oxidizing atmosphere has resulted in impurity phases. As the doping level of $\mathrm{Y}$ is selected to be $0.08 \mathrm{~mol} \%, \mathrm{Nb}$ content is restricted to be lower than $0.05 \mathrm{~mol} \%$ in order to obtain a single-phase perovskite. However, $\mathrm{Y}_{2} \mathrm{Ti}_{2} \mathrm{O}_{7}$ impurity is still observed in all Y and Nb co-doped SYTN samples (Figure S2a). In practical use, one side of the IC layer is facing a low oxygen partial pressure. When the powder precursors are synthesized in a reducing atmosphere, the formation of impurity is suppressed effectively (Figure S2b). Reduction of oxidation state of $\mathrm{Ti}^{4+}$ and $\mathrm{Nb}^{5+}$ suppresses impurity by promoting $\mathrm{Y}$ and $\mathrm{Ti}$ in $\mathrm{Y}_{2} \mathrm{Ti}_{2} \mathrm{O}_{7}$ to dissolve back into the $\mathrm{SYTN}$ lattice. However, the $\mathrm{Y}_{2} \mathrm{Ti}_{2} \mathrm{O}_{7}$ impurity in $\operatorname{SYTN}\left(\mathrm{Y}_{0.08} \mathrm{Nb}_{0.03}\right)$ powders cannot be completely removed by heat treatment in $5 \% \mathrm{H}_{2} / \mathrm{N}_{2}$. It is noteworthy that the color of the air calcined SYTN powders is white but turns into grey after reduction. 

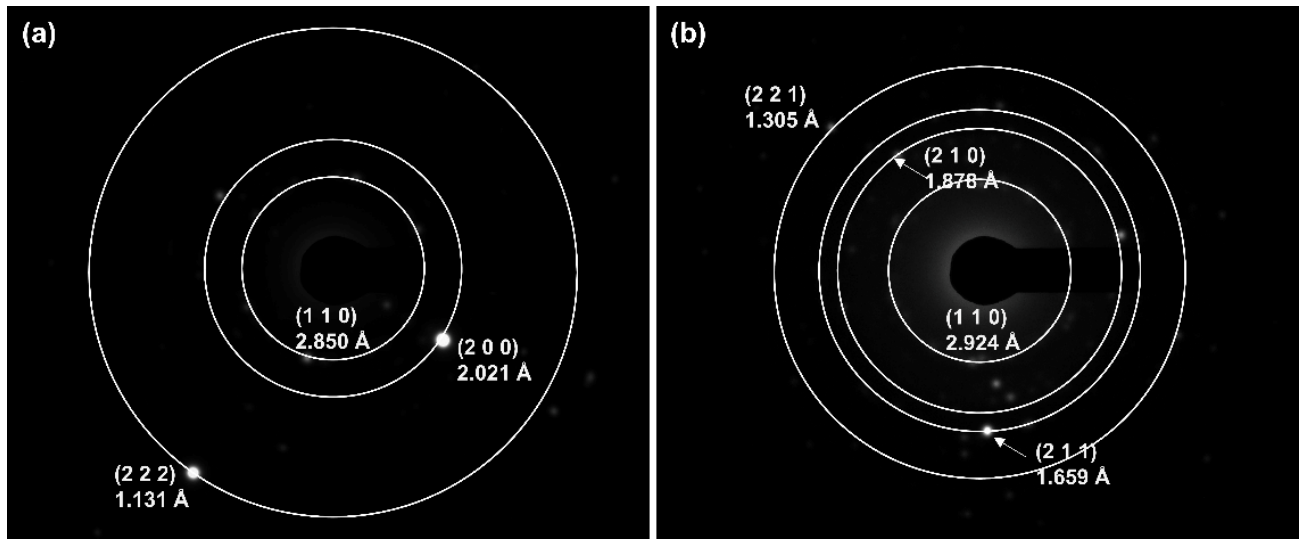

Figure S3 SAED patterns of (a) air-SYTN $\left(\mathrm{Y}_{0.08} \mathrm{Nb}_{0.02}\right)$ and (b) $5 \% \mathrm{H}_{2} / \mathrm{N}_{2}-\mathrm{SYTN}\left(\mathrm{Y}_{0.08} \mathrm{Nb}_{0.02}\right)$.

Figure $\mathbf{S 3}$ shows the SAED patterns of $\operatorname{SYTN}\left(\mathrm{Y}_{0.08} \mathrm{Nb}_{0.02}\right)$ prepared in oxidizing and reducing atmospheres. The $d$-spacing of undoped $\mathrm{SrTiO}_{3}$ along the (110) plane is $2.756 \AA$. Y and $\mathrm{Nb}$ codoping in SYTN leads to a lattice expansion. The d-spacing of $\operatorname{SYTN}\left(\mathrm{Y}_{0.08} \mathrm{Nb}_{0.02}\right)$ calcined in air along the (110) plane is found to be $2.85 \AA$, while the corresponding d-spacing of $\operatorname{SYTN}\left(\mathrm{Y}_{0.08} \mathrm{Nb}_{0.02}\right)$ calcined in $5 \% \mathrm{H}_{2} / \mathrm{N}_{2}$ is $2.924 \AA$, which indicates a lattice expansion upon reduction. 
Table S1 Summary of refined structural parameters for air-SYTN $\left(\mathrm{Y}_{0.08} \mathrm{Nb}_{0.02}\right)$ and $5 \% \mathrm{H}_{2} / \mathrm{N}_{2}-\mathrm{SYTN}\left(\mathrm{Y}_{0.08} \mathrm{Nb}_{0.02}\right)$.

\begin{tabular}{cc|cc}
\hline & & air- & $5 \% \mathrm{H}_{2} / \mathrm{N}_{2-}$ \\
& & SYTN $\left(\mathrm{Y}_{0.08} \mathrm{Nb}_{0.02}\right)$ & $\mathrm{SYTN}\left(\mathrm{Y}_{0.08} \mathrm{Nb}_{0.02}\right)$ \\
\hline Space group & & $P m-3 m$ & $P m-3 m$ \\
Unite-cell & $a(\AA)$ & 3.8992 & 3.8998 \\
parameters & $b(\AA)$ & 3.8992 & 3.8998 \\
& $c(\AA)$ & 3.8992 & 3.8998 \\
& $\mathrm{Sr}$ & $0,0,0$ & $0,0,0$ \\
Atom sites & $\mathrm{Y}$ & $0,0,0$ & $0,0,0$ \\
& $\mathrm{Ti}$ & $0.5,0.5,0.5$ & $0.5,0.5,0.5$ \\
& $\mathrm{Nb}$ & $0.5,0.5,0.5$ & $0.5,0.5,0.5$ \\
& $\mathrm{O}$ & $0,0.5,0.5$ & $0,0.5,0.5$ \\
Occupancy & $\mathrm{Sr}$ & 0.912 & 0.912 \\
& $\mathrm{Y}$ & 0.078 & 0.078 \\
& $\mathrm{Ti}$ & 0.968 & 0.968 \\
$R_{\mathrm{p}}(\%)$ & $\mathrm{Nb}$ & 0.019 & 0.019 \\
$R_{\mathrm{wp}}(\%)$ & $\mathrm{O}$ & 1 & 0.989 \\
$\chi^{2}$ & & 5.6 & 3.2 \\
Impurity content & & 6.9 & 4.6 \\
\hline
\end{tabular}

Cell expansion in reducing atmosphere observed by XRD refinement further confirmed the reduction of $\mathrm{Ti}$ and $\mathrm{Nb}$. 

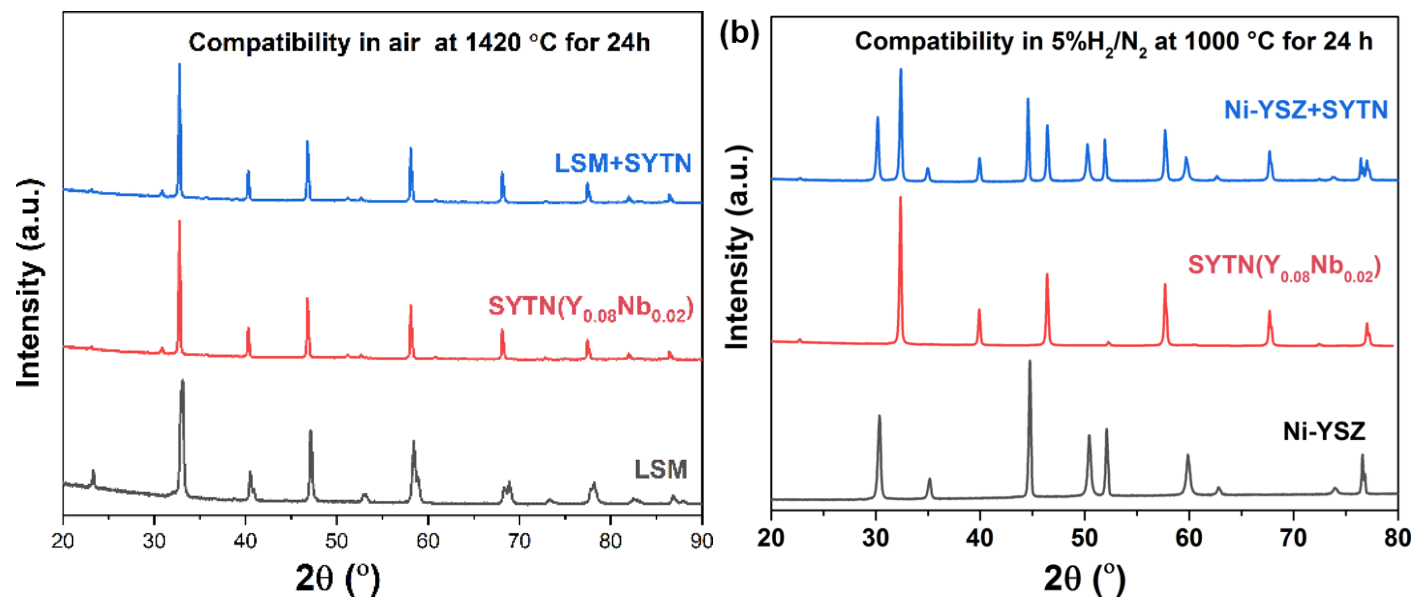

Figure S4 Chemical compatibility between (a) LSM and SYTN at $1420{ }^{\circ} \mathrm{C}$ for $24 \mathrm{~h}$ in air, and (b) Ni-YSZ and SYTN at $1000{ }^{\circ} \mathrm{C}$ for $24 \mathrm{~h}$ in $5 \% \mathrm{H}_{2} / \mathrm{N}_{2}$.

Figure S4 shows that SYTN has excellent chemical compatibility with the adjacent materials. 

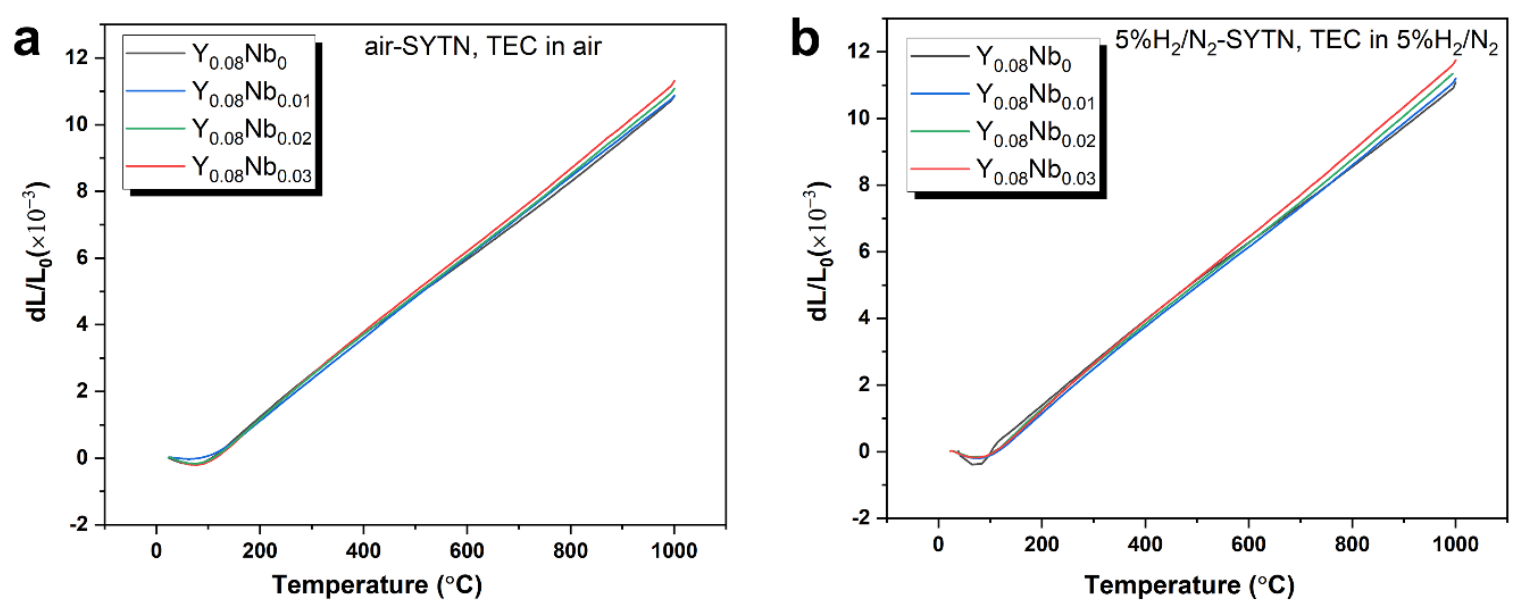

Figure S5 Thermal expansion curve of (a) air-SYTN ( $\mathrm{Y}=0.08, \mathrm{Nb}=0,0.01,0.02,0.03)$ in air; (b) $5 \% \mathrm{H}_{2} / \mathrm{N}_{2}-\mathrm{SYTN}$ ( $\mathrm{Y}=0.08, \mathrm{Nb}=0,0.01,0.02,0.03$ ) in $5 \% \mathrm{H}_{2} / \mathrm{N}_{2}$. The thermal expansion coefficient (TEC) of air-SYTN with increasing Nb contents are observed to be $11.6,11.8,11.9$ and $12.1 \times 10^{-6} / \mathrm{K}$, respectively. The TEC of $5 \% \mathrm{H}_{2} / \mathrm{N}_{2-}$ SYTN with increasing $\mathrm{Nb}$ contents are $11.9,12.1,12.2$ and $12.3 \times 10^{-6} / \mathrm{K}$, respectively. 